\title{
RICE GRAIN YIELD ESTIMATION OVER SOME ASIAN COUNTRIES USING ISRO'S SCATSAT-1 KU-BAND SCATTEROMETER DATA
}

\author{
Rojalin Tripathy $^{1 *}$, B. K. Bhattacharya ${ }^{1}$, Preeti Tahlani ${ }^{2}$, Pushkar Gaur ${ }^{2}$, S. S. Ray ${ }^{2}$ \\ ${ }^{1}$ Space Applications Centre, ISRO, Ahmedabad, India - (rose_t, bkbhattacharya)@sac.isro.gov.in \\ ${ }^{2}$ Mahalanobis National Crop Forecasting Centre, New Delhi, India - preeti.tahlani@gov.in, gaur.pushkar8@gmail.com, \\ shibendu.ncfc@nic.in,
}

Commission III, WG III/10

KEY WORDS: Rice yield, rice planting date, SCATSAT-1, Ku-band, sigma-0, regression model, CCE data

\begin{abstract}
:
Rice crop monitoring and yield prediction at country-scale can be effectively done using high-repeat active microwave remote sensors due to its all-weather observation capability of land surface. The Ku-band with a frequency of $13.515 \mathrm{GHz}$ has the ability to interact with the surface layer and hence is useful for providing information on top portion of canopy and hence the grain and awns of rice crop. Also it has the capability to generate information over the whole region of South Asia in one day. Hence the present study was carried out to explore the super resolved $\mathrm{Ku}$ band back scattering coefficient from space borne scatterometer (SCATSAT1) for rice productivity assessment over six Asian countries (India, Pakistan, Nepal, Bangladesh, Myanmar and Sri Lanka). The super resolved sigma-0 in both polarization ( $\mathrm{H}$ and $\mathrm{V}$ ) for the kharif rice season of 2017 (May to Mid-Nov) was used for this study. The temporal backscatter was used to generate rice planting date using polynomial fitting. Multiple regression models were developed using the daily SH/SV ratio and the farm-level fresh paddy yield collected through the Crop Cutting Experiment (CCE). The validation of the model was done for India at state level. For other countries national average reported yield was compared with the estimated yield. The rice planting date was found to vary from first week of June to last week of August in different parts of the six countries. Country average yield was found to vary from $3.45 \mathrm{t}$ ha-1 in Sri Lanka to $4.32 \mathrm{t}$ ha-1 in Myanmar. The absolute difference was lowest in India ( $8 \%$ ) followed by Sri Lanka (-11\%) and maximum in Nepal (35\%). In Indian states, the validation results showed a correlation coefficient of 0.95 at state level with a RMSE of 0.28 tha- 1 ( $11.4 \%$ of mean reported yield). This study showed the possibility of using high frequency and high resolution Ku-band back scattering coefficient for rice grain yield estimation at continental scale such as Asia. The yield estimation can be further improved with the use of country-wise crop cutting data for model development and validation.
\end{abstract}

\section{INTRODUCTION}

South Asia comprising of Bangladesh, Bhutan, India, Nepal, Pakistan, and Sri Lanka accounts for almost $40 \%$ of the world's harvested rice area and almost $25 \%$ of the world's population (Gumma et al. 2011). The population of the region is projected to grow faster than its ability to produce sufficient rice to meet the demand making South Asia food insecure in coming decades (Papademetriou, 2000). Thus, rice-based agricultural systems are a vital component of any strategy to ensure food security in this region. Monitoring rice growth and predicting rice yield over a large region like South Asia before harvest will provide valuable information to planners, decision makers, and scientists to find out zones of low and high yield in that region so that export import decision can be made. Also proper management may be planned specifically for the regions of low yield if it can be known prior to harvest.

Majority of the rice crop is cultivated in kharif season when there is adequate rainfall and typically with cloud cover in the whole season. Microwave energy from an active sensor is able to penetrate cloud and rainfall to some extent depending upon their frequency and wavelength. India has the operational programme of National Rice Crop Monitoring that used multidate RISAT - 1 (C-band, $5.3 \mathrm{GHz}$ and $\mathrm{HH}, \mathrm{HV}$ polarisation) data as well as sentinel-1 with $\mathrm{C}$-band SAR to estimate rice area; and uses optical remote sensing and weather based model for providing rice yield operationally at Mahalanobis National

* Corresponding author
Crop Forecasting Centre (MNCFC). New researches are now oriented towards exploring the feasibility of estimating rice crop yield from microwave backscatter data from scatterometer due to their high temporal resolution and more spatial coverage. The Ku-band with a frequency of $13.515 \mathrm{GHz}$ has the ability to interact with the surface layer and hence is useful for providing information on top portion of canopy and hence the grain and awns of rice crop. $\mathrm{Ku}$ band scatterometer data has been used by many researchers for exploring it's capability in crop research especially for cereal grain crops (Ringelmann et al. 2004; Oza and Parihar, 2007; Inoue et al., 2002). These researches used data from space based and ground based platforms and showed the utility of the Ku-band backscatter for estimating planting date of wheat and rice as well as for fresh grain yield of rice.

Ku-band scatterometer from SCATSAT-1 provides global coverage within 2 days, thus has the advantage to generate this information more frequently. The availability of high spatial or super resolution $(2 \mathrm{~km})$ back scattering data of the $\mathrm{Ku}$-band in $\mathrm{VV}$ and HH polarization from SCATSAT-1 platform made this data more useful as compared to the data at its original resolution $(25 \mathrm{~km})$. SCATSAT-1 satellite carrying $\mathrm{Ku}$ band Scatterometer was launched on 26th September, 2016. It provides backscattering coefficient (sigma-naught) over whole globe and wind vector over ocean surface. The instrument is a pencil beam wind Scatterometer operating at Ku-band of 13.515 GHz. The two pencil beams, inner and outer, result in a constant angle of incidence for both beams; this allows $\sigma 0$ measurements at multiple (4 or 2 ) azimuth angles for the same point on the ocean surface. 
Variations of the radar scatterometer signal are mainly caused by changes of the dielectric properties of the scattering surface and by changes of the scattering mechanism as introduced by changes of surface roughness and contributions by mainly surface scattering. For vegetation, the main reasons of these variations are changes in moisture and the change in top canopy structure due to growth of vegetation. Microwave energy in short wavelength SAR as in $\mathrm{Ku}$ and $\mathrm{X}$ band interact mainly with the top portion of the canopy layers, thus are useful to estimate important plant parameters such as fresh grain weight and grain yield (Moran et al., 1998; Brisco and Brown, 1998). Also it has the capability to generate information over the whole region of South Asia in one day.

Looking at the need for the rice yield prediction over South Asia and the potential of back scatter data from $\mathrm{Ku}$ band scatterometer of SCATSAT-1 satellite for the same the present study was carried out to explore the super resolved $\mathrm{Ku}$ band back scattering coefficient from space borne scatterometer onboard SCATSAT-1 for rice productivity assessment in the six important South Asian countries.

\section{STUDY AREA}

The study area comprises of six major rice growing South Asian countries, viz., India, Pakistan, Nepal, Bangladesh, Myanmar and Sri Lanka (Fig. 1). The capability of the scatterometer to scan the whole region daily inspired us to take this broad study area. The study area differs in terms of climate, soil and rice ecosystems. Climate of the study area varies from subtropical in Bangladesh and East India to semiarid temperate in N-India and Nepal. Soil varies from loamy sand to clayey. Rice ecosystem includes lowland rainfed system, irrigated system, deep water system as well as upland systems. The seasonal pattern of precipitation is driven by the monsoon climatic system in the region. It brings rain during May to September.

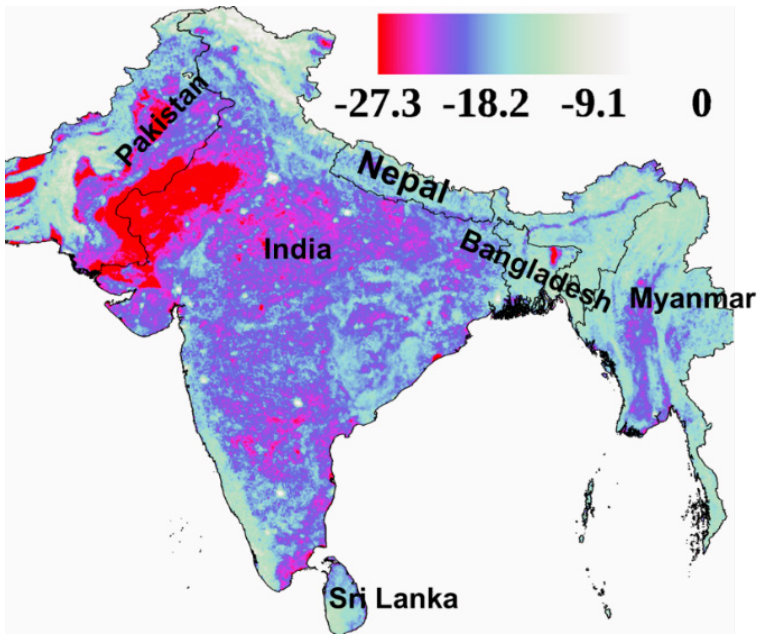

Figure 1. Sigma-0 from Ku band scatterometer of SCATSAT-1 in HH Polarization over the study area with the country boundary

\section{DATA}

The study used both satellite and field based experimental data (Table 1). SCATSAT-1 satellite carrying $\mathrm{Ku}$ band Scatterometer provides backscattering coefficient (sigma- naught) over whole globe and wind vector over ocean surface at $25 \mathrm{~km}$ original resolution. The instrument is a pencil beam wind Scatterometer operating at Ku-band of $13.515 \mathrm{GHz}$. SCATSAT-1 Data Products System is operational at NRSC, Shadnagar. L1B products are scan-mode products $(\sim 6 \times 30 \mathrm{~km}$ spatial resolution). L2A and L2B are swath-gridded products $(50 \times 50$ and $25 \times 25 \mathrm{~km})$ while L3 products are generated on a global grid. Super resolution backscattering coefficient (L4_India) is being generated at Space Applications Centre at $2 \mathrm{kmx} 2 \mathrm{~km}$ resolution using the Scatterometer Image Reconstruction (SIR) resolution enhancement algorithm (Long and Daum, 1997). For details of the procedure, readers may refer (Modi and Padia, 2015, Modi, 2016). This super resolved sigma-0 in both polarization ( $\mathrm{H}$ and $\mathrm{V}$ ) for the kharif rice season of 2017 (May to Mid-Nov) was used for this study.

\begin{tabular}{|c|c|}
\hline Input (Baseline data) & Source \\
\hline $\begin{array}{l}\text { Daily SCATSAT- L4 data } \\
\text { product of Sigma-0 in horizontal } \\
\text { (SH) and vertical (SV) } \\
\text { polarization over kharif rice } \\
\text { season }\end{array}$ & $\begin{array}{l}\text { MOSDAC } \\
\text { (www.mosdac.gov.in) }\end{array}$ \\
\hline Kharif rice crop mask & $\begin{array}{l}\text { MNCFC (India) and } \\
\text { IRRI published data } \\
\text { (Nelson et al., 2015) } \\
\text { (other countries) }\end{array}$ \\
\hline $\begin{array}{l}\text { Crop Cutting Experiment data } \\
\text { over India }\end{array}$ & $\mathrm{MNCFC}$ \\
\hline $\begin{array}{l}\text { Reported yield (past five years } \\
\text { reported yield by DES for India) } \\
\text { data }\end{array}$ & $\begin{array}{l}\text { www.dacnet.in, } \\
\text { FAOSTAT, } 2018\end{array}$ \\
\hline $\begin{array}{l}\text { Village, Block, District and state } \\
\text { boundaries }\end{array}$ & In-house SAC \\
\hline
\end{tabular}

\section{METHODOLOGY}

The temporal backscatter was used to generate rice planting date using polynomial fitting. Multiple regression models were developed for each of the 12 rice growing states in India representing different agro-climatic zones and water management practices using the daily $\mathrm{SH} / \mathrm{SV}$ ratio and the farm-level fresh paddy yield collected through the Crop Cutting Experiment (CCE). In total 1042 CCE yield were collected form the 10 states of India and used for developing the pooled model (Table 2).

\begin{tabular}{|l|l|l|}
\hline State & No of CCE point & Source \\
\hline Bihar & 588 & CYMMIT \\
\hline Chhattisgarh & 47 & MNCFC \\
\hline Haryana & 31 & MNCFC \\
\hline Jharkhand & 4 & MNCFC \\
\hline Karnataka & 47 & MNCFC \\
\hline Odisha & 103 & MNCFC \\
\hline Punjab & 51 & MNCFC \\
\hline Telengana & 36 & MNCFC \\
\hline Uttar Pradesh (UP) & 49 & MNCFC \\
\hline West Bengal (WB) & 86 & MNCFC \\
\hline Total & 1042 & \\
\hline
\end{tabular}

Table 2. State wise no of CCE data 
State-wise models also were developed for the 10 Indian states using the respective CCE yield and corresponding SH/SV ratio. The models for West Bengal and Bihar states were applied to estimate fresh rice grain yield of Bangladesh and Nepal, respectively while the pooled rice grain yield model was applied for other three countries. The model for India was used to estimate rice yield of other countries due to lack of CCE data in other countries. Rice mask for all countries except for India was taken from published data of IRRI, Phillipines (Nelson et al., 2015). For India rice mask was taken from MNCFC, New Delhi.

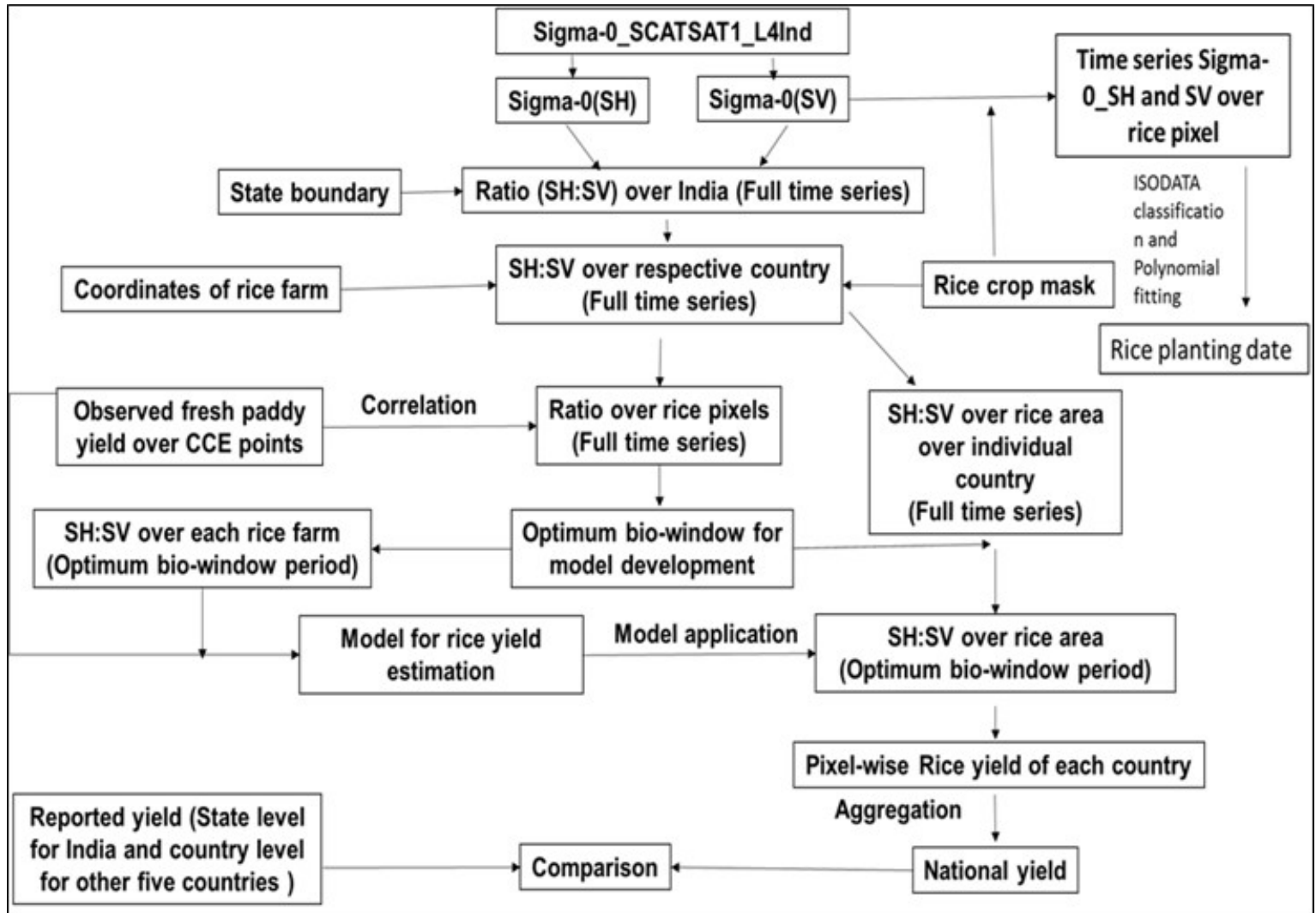

Figure 2. Approach and methodology for rice yield prediction with SCATSAT-1 data
The validation of the model was done for India at state and district level. For other countries national average reported yield was compared with the estimated yield. Overall methodology is given in fig 2.

\section{RESULTS AND DISCUSSION}

\subsection{Temporal behaviour of $\mathrm{Ku}$ band backscatter at state} level

The time series plots of sigma- 0 in VV polarization in Punjab and West Bengal with contrasting water management is shown in fig 3. The time series sigma- 0 showed a dual peak (one at maximum tillering stage and other at grain filling stage) and dual minima (one just prior to transplanting and one at the maximum LAI stage) in both the states. This may be due to the change in roughness of the rice morphology such as increase in roughness after the first minima coincides with the flooding stage (transplanting stage) due to increase in tiller number till the maximum tillering stage where the curve reaches the first maxima, followed by increase in smoothness due to leaf coverage resulted in the second minima at peak LAI. Thereafter, there is an increase in roughness due to development of panicles till the grain filling stage thus causing the second maxima followed by reduction in roughness due to covering of canopy with the rice grains till harvest.
The plots showed that peaks and minima's are more prominent in Punjab as compared to those in West Bengal. In Punjab, rice crop is grown in irrigated condition in which soil becomes wet first rather than the top canopy. Hence, in Punjab, the roughness of crop canopy is only due to the rice structure and hence gives rise to a sharp peak; while reverse is in the case of West Bengal where the majority of rice area is rain-fed and rainwater affects the moisture content of the top canopy, reduces the roughness and the interactive signature results in number of peaks and drops as per the rainfall event. It may also be due to the fact that in Punjab rice is grown only in kharif season while in West Bengal both rabi and kharif season rice crops were contributing to the mixed signature of mature (rabi) and new (kharif) crops (fig 3). 


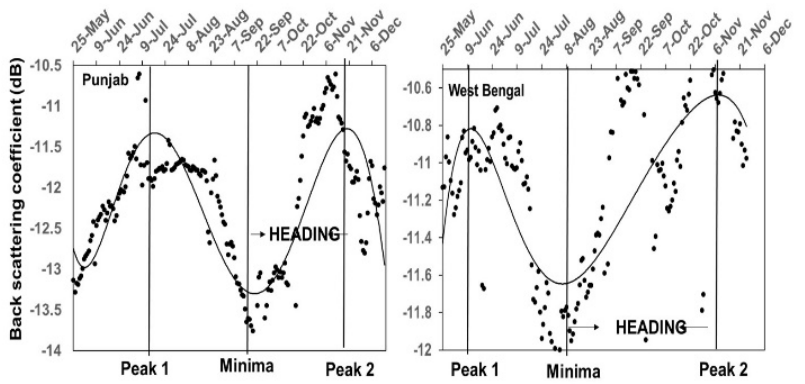

Figure 3. Temporal profile of sigma-0 (SV) over rice areas in Punjab and West Bengal

\subsection{Rice planting date}

The rice planting date was found to vary from first week of June to first week of August in different states of India. In Bangladesh the planting date varied from 11 July to 25 August in different parts during the Aman season. In Sri Lanka planting date varied from 29 June to 10 August; in Pakistan from 14 June to 26 June; in Myanmar from 11 June to 27 July and in Nepal it varied from 26 June to 27 July during 2017 (Fig 4).



Figure 4. Planting date of rice in six South Asian countries

\subsection{Yield model development}

The details of the structure and coefficient of the state model are given in this section.

\subsubsection{Structure of the Model for different state and the pooled model:}

For UP and WB

Ypaddy $=a * X 1+b * X 2+c * X 3+d * X 4+e * X 5+C$

For Telangana, Haryana, Odisha

Ypaddy $=a^{*} X 1+b * X 2+c * X 3+d * X 4+e^{*} X 5+f^{*} X 6+C$

For Chhattisgarh,

Ypaddy $=\mathrm{a} * \mathrm{X} 1+\mathrm{b} * \mathrm{X} 2+\mathrm{c} * \mathrm{X} 3+\mathrm{d} * \mathrm{X} 4+\mathrm{e} * \mathrm{X} 5+\mathrm{f} * \mathrm{X} 6+\mathrm{g} * \mathrm{X} 7+\mathrm{C}$

For Bihar and Karnataka,

Ypaddy $=\mathrm{a} * \mathrm{X} 1+\mathrm{b} * \mathrm{X} 2+\mathrm{c} * \mathrm{X} 3+\mathrm{d} * \mathrm{X} 4+\mathrm{e} * \mathrm{X} 5+\mathrm{f} * \mathrm{X} 6+\mathrm{g} * \mathrm{X} 7$

$+\mathrm{h} * \mathrm{X} 8+\mathrm{i} * \mathrm{X} 9+\mathrm{C}$

For Punjab,
Ypaddy $=a * X 1+b * X 2+c * X 3+d * X 4+e^{* X} 5+f^{* X} 6+g * X 7+$
$h * X 8+i * X 9+j * X 10+k^{*} X 11+l^{* X} 12+C$

Pooled model

Ypaddy $=\mathrm{a} * \mathrm{X} 1+\mathrm{b} * \mathrm{X} 2+\mathrm{c} * \mathrm{X} 3+\mathrm{d} * \mathrm{X} 4+\mathrm{e} * \mathrm{X} 5+\mathrm{C}$

From Ypaddy, Ygrain was computed using the following equation-

Ygrain = Ypaddy X Mw X MF

Where $\quad$ Ygrain $=$ rice grain yield $(\mathrm{t}$ ha- 1$)$

Ypaddy $=$ fresh paddy yield ( $\mathrm{t}$ ha-1)

$\mathrm{Mw}=$ moisture content in grain by weight $(\%)$

$\mathrm{a}, \mathrm{b}, \mathrm{c}, \mathrm{d}, \mathrm{e}, \mathrm{f}, \mathrm{g}, \mathrm{h}, \mathrm{i}, \mathrm{j}, \mathrm{k}, \mathrm{l}$ are the coefficients for X1, $\mathrm{X} 2, \mathrm{X} 3, \mathrm{X} 4, \mathrm{X} 5, \mathrm{X} 6, \mathrm{X} 7, \mathrm{X} 8, \mathrm{X} 9, \mathrm{X} 10, \mathrm{X} 11, \mathrm{X} 12$, respectively

$\mathrm{X} 1$----X12 for each state are the SH/SV at different calendar day

$\mathrm{C}=$ constant

The dates of X1----X12 for each state are given in Table 3a and the corresponding coefficients are given in Table $3 \mathrm{~b}$.

\begin{tabular}{|l|r|r|r|r|r|r|r|r|r|r|}
\hline & \multicolumn{10}{|c|}{ Calendar day for which SHSV was used as input } \\
\cline { 2 - 11 } X1 & Bihar & Chhattisgart & Haryana & Kamataka & Odisha & Punjab & Telangana & UP & WB & Pooled \\
\cline { 2 - 11 } X2 & 158 & 212 & 189 & 143 & 181 & 145 & 180 & 157 & 145 & 105 \\
X3 & 168 & 225 & 212 & 147 & 254 & 168 & 211 & 178 & 150 & 145 \\
X4 & 216 & 252 & 235 & 155 & 257 & 173 & 248 & 194 & 180 & 155 \\
X5 & 224 & 267 & 261 & 169 & 278 & 194 & 270 & 278 & 250 & 164 \\
X6 & 236 & 282 & 297 & 201 & 287 & 211 & 280 & 301 & 287 & 180 \\
X7 & 255 & 292 & 307 & 231 & 298 & 242 & 293 & & & \\
X8 & 262 & 116 & & 238 & & 258 & 314 & & & \\
X9 & 294 & 116 & & 245 & & 271 & & & & \\
X10 & & & & 263 & & 280 & & & & \\
X11 & & & & & & 286 & & & & \\
X12 & & & & & & 292 & & & & \\
\hline
\end{tabular}

Table 3a: Inputs for the rice yield model of 9 states and pooled model

\begin{tabular}{|c|c|c|c|c|c|c|c|c|c|c|}
\hline & \multicolumn{10}{|c|}{ Coefficients } \\
\hline & Bihar & Chhattisg arh & Haryana & Kamataka & Odisha & Punjab & $\begin{array}{c}\text { Telang an } \\
a\end{array}$ & UP & WB & Pooled \\
\hline a & 1.73 & -3.86 & -12.25 & 7.83 & -6.37 & .3 .94 & -1.53 & -17.14 & 8.89 & .3 .39 \\
\hline b & 2.84 & -4.03 & 9.05 & -12.25 & 697 & -3.79 & 0.58 & 8.98 & 9.44 & 3.46 \\
\hline c & -125 & 7.39 & -4.26 & 9.07 & -2.24 & -5.94 & -1.93 & 10.81 & 4.80 & 1.46 \\
\hline d & -0.17 & 7.07 & 9.62 & -6.62 & 12.02 & 0.45 & 3.52 & 14.58 & -7.42 & 7.15 \\
\hline e & $-1,37$ & -8.97 & -6.36 & 1.37 & 7.065 & 3.79 & -1.92 & 11.73 & 4.87 & 397 \\
\hline$f$ & -0.53 & 0.87 & -1.69 & -0.30 & -0.394 & -5.00 & 6.34 & & & \\
\hline 8 & 2.53 & 2.05 & & 11.25 & & 4.40 & 7.44 & & & \\
\hline h & -0.94 & & & 15.76 & & 2.20 & & & & \\
\hline $\mathrm{i}$ & 0.08 & & & 152 & & 4.52 & & & & \\
\hline j & & & & & & 5.10 & & & & \\
\hline$k$ & & & & & & 2.72 & & & & \\
\hline 1 & & & & & & 3.37 & & & & \\
\hline C & $=0.59$ & 2.78 & 11.42 & .17 .59 & -9.64 & 10.59 & -3.65 & 24.74 & 3.30 & 4.12 \\
\hline
\end{tabular}

Table 3b: Coefficients of the regression model for the 9 states and pooled model

Among different states, the highest R2 of the daily model was obtained for Haryana state (0.87) and lowest was observed in Bihar (0.35). This could be due to the large number of observations $(n=394)$ used for model development on Bihar state (Table 4).

\begin{tabular}{|l|l|l|}
\hline State & $\begin{array}{c}\text { Correlation } \\
\text { coefficient }(r)\end{array}$ & $\begin{array}{c}\text { No of } \\
\text { observation } \\
(n)\end{array}$ \\
\hline Jharkhand & 0.345 & 394 \\
Chhattisgarh & 0.618 & 26 \\
Haryana & 0.865 & 26 \\
Karnataka & 0.797 & 26 \\
Odisha & 0.599 & 42 \\
Punjab & 0.796 & 41 \\
\hline
\end{tabular}




\begin{tabular}{|l|l|l|}
\hline Telangana & 0.536 & 33 \\
Uttar Pradesh & 0.551 & 33 \\
West Bengal & 0.644 & 22 \\
\hline
\end{tabular}

Table 4: Correlation coefficient of the models for nine Indian state and the no of CCE data used for model development

The coefficient of determination (R2) for rice yield prediction was found to be significant at $95 \%$ for all the 12 states of India with $\mathrm{R}^{2}$ varying between 0.35 and 0.87 (Table 4 ).

\subsection{Model Application and spatial yield map generation}

Above developed models were applied as mentioned in the methodology section. Pixel wise paddy yield found to vary between 1 to 7.5 tha $^{-1}$ in the six countries under study (fig 5). Country average yield was found to vary from $3.45 \mathrm{t}$ ha-1 in Sri Lanka to $4.32 \mathrm{t} \mathrm{ha}^{-1}$ in Myanmar.

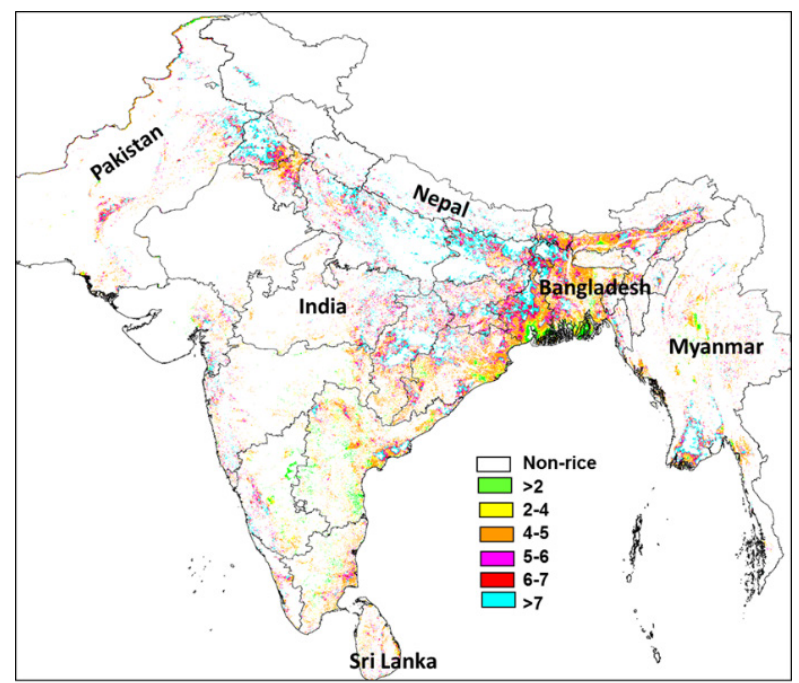

Figure 5. Rice grain yield $\left(\mathrm{t} \mathrm{ha}^{-1}\right)$ of six South Asian countries at $2 \mathrm{~km}$ resolution using backscatter from SCASAT-1

\subsection{Validation with reported yield}

The models were validated with the reported yield (last fiveyear average) at state level in India and country level for other countries. For India at state level, the average deviation between the estimated yield with over the 12 states were found to be $6.05 \%$. The correlation coefficient was found to be 0.95 while the RMSEs at state level were found to be $0.28 \mathrm{t} \mathrm{ha}^{-1}(11.24 \%)$, respectively (fig 5). Absolute difference between the estimated yield and that of reported yield remained less than $20 \%$ in all states, maximum in Bihar (19\%) and minimum in Chhatishgarh $(0.57 \%)$.

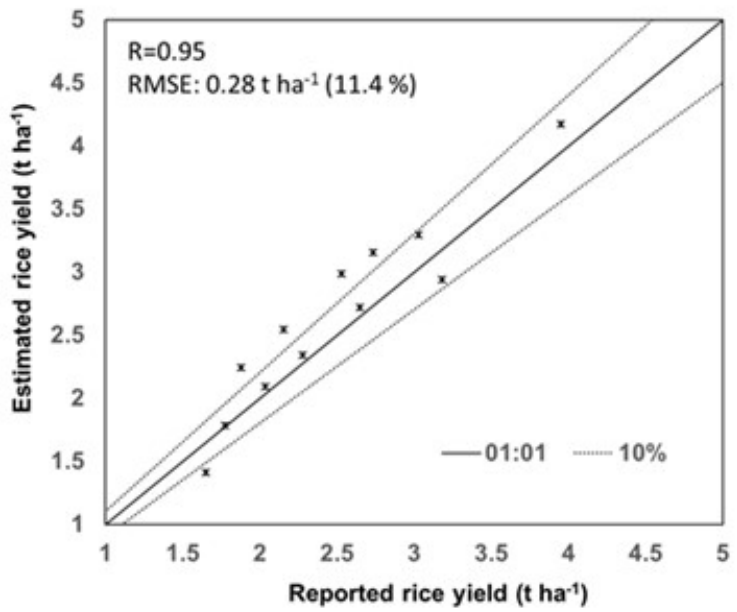

Fig 6. Comparison of state level rice yield estimated from the pixel model with the reported yield

The absolute difference was lowest in India ( $8 \%$ ) followed by Sri Lanka (-11\%) and maximum in Nepal (35\%) (Fig 7).

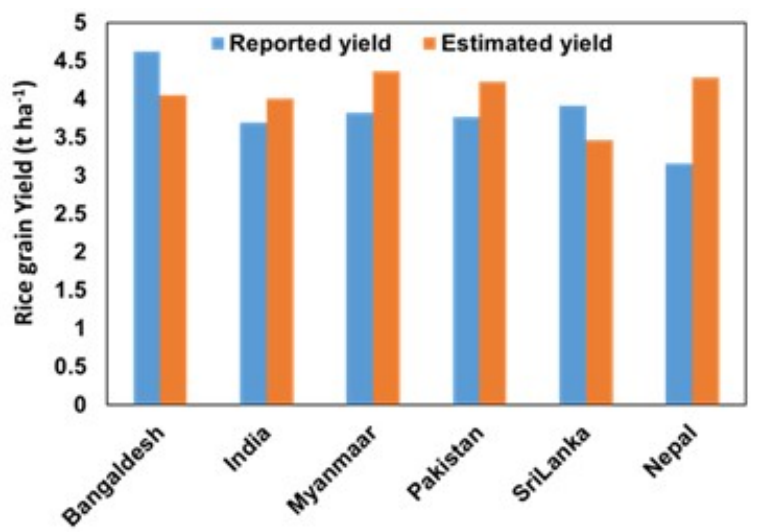

Fig 7: Comparison of estimated rice yield using SCATSAT-1 backscatter and reported rice yield at national level yield in six South Asian countries

\section{CONCLUSIONS}

This study showed the possibility of using high frequency and high resolution $\mathrm{Ku}$-band back scattering coefficient for rice grain yield estimation at continental scale such as Asia. It can be concluded that owing to the high temporal resolution, the selection of bio-window was easy and accurate as compared to other data with low temporal resolution and can be used for national and state level yield forecasting in India and South Asia. The yield estimation can be further improved with the use of country-wise crop cutting data (especially for Nepal) for model development and validation.

\section{ACKNOWLEDGEMENT}

We are thankful to Director SAC for his keen interest and encouragement for the application research using scatterometer data from SCATSAT-1. Our sincere thanks are due to the project coordinator, SCATSAT-1 utilization project for his constructive suggestion for proper utilization of the SCATSAT1 sigma-0 product for various applications. We acknowledge the SCATSAT-1 data product team of SAC for the high 
resolution $\mathrm{Ku}$ band scatterometer data from SCATSAT1 and CYMMIT, India for the crop cutting yield data of Bihar.

\section{REFERENCES}

Brisco, B., Brown, R.J., 1998. Agricultural applications with radar. In Principles and Applications in Imaging Radar, F.M. Henderson and A.J. Lewis (Eds), pp. 381-406 (New York: Wiley)

Gumma, Murali Krishna, Nelson, Andrew Prasad, Thenkabail, S. and Singh, Amrendra N. 2011. Mapping rice areas of South Asia using MODIS multitemporal data. Journal of Applied Remote Sensing, 5: 053547-1-26.

Inoue, Y., Kurosu, T., Maeno, H., Uratsuka, S., Kozu, T., Dabrowsk-Zielinska, K., Q I, J., 2002. Season-long daily measurements of multi-frequency $(\mathrm{Ka}, \mathrm{Ku}, \mathrm{X}, \mathrm{C}$, and $\mathrm{L})$ and full-polarization backscatter signatures over paddy rice field and their relationship with biological variables. Remote Sensing of Environment, 81: pp. 194-204.

Long, D.G., Daum, D., 1997. Spatial Resolution Enhancement of SSM/I Data. IEEE Trans. Geosci. Rem. Sens., 36: pp. 407417.

Modi Jalpa, 2016. Evaluation of OSCAT high resolution sigma0 products generated at SAC Scientific report, SAC/SIPG/MDPD/SCAT-DP/TN-01/Mar. 2016.

Modi Jalpa, Padia, Kirti, 2015. Generation of high resolution sigma0 through algebraic reconstruction, Scientific report/SAC/SIPA/DPSG/AIPD/TN-09/Jul., 2015.

Moran, M.S., Vidal, A., Troufleau, D., Inoue, Y., Mitchell, T.A., 1998. Ku- and C-band SAR for discriminating agricultural crop and soil conditions. IEEE Transactions on Geoscience and Remote Sensing, 36: pp. 265-272.

Nelson, Andrew, Gumma, Murali Krishna.2015. A map of lowland rice extent in the major rice growing countries of Asia. 37p. IRRI, Los Banos, Philippines.

Oza, S. R., Parihar, J. S., 2007. 'Evaluation of Ku-band QuikSCAT scatterometer data for rice crop growth stage assessment. International Journal of Remote Sensing, 28:16, pp. $3447-3456$

Papademetriou, M.K., 2000. RiceproductionintheAsia-Pacific region: issues and perspectives. In: Bridging the Rice Yield Gap in the Asia-Pacific Region, M. K. Papademetriou, F. J. Dent and E.M.Herath,Eds., Bangkok, Food and Agriculture Organization of the United Nations, p. 220.

Ringelmann, N., Scipal, K., Bartalis, Z. and Wagner, W., 2004. Planting date estimation in semi-arid environments based on Ku-band radar scatterometer data. In: IGARRS'2004, Anchorage, USA. 